\title{
ATMOSPHERIC ENVIRONMENT
}

\section{Characterization of urban and rural organic particulate in the Lower Fraser Valley using two Aerodyne Aerosol Mass Spectrometers}

\author{
M. Rami Alfarra ${ }^{\mathrm{a}, *}$, Hugh Coe ${ }^{\mathrm{b}}$, James D. Allan ${ }^{\mathrm{b}}$, Keith N. Bower ${ }^{\mathrm{b}}$, \\ Hacene Boudries $^{c}$, Manjula R. Canagaratna ${ }^{c}$, Jose L. Jimenez ${ }^{\mathrm{d}}$, John T. Jayne ${ }^{\mathrm{c}}$, \\ Arthur A. Garforth ${ }^{\mathrm{a}}$, Shao-Meng Li ${ }^{\mathrm{e}}$, Douglas R. Worsnop ${ }^{\mathrm{c}}$ \\ ${ }^{a}$ Department of Chemical Engineering, University of Manchester Institute of Science and Technology (UMIST), \\ P. O. Box 88, Manchester M60 1QD, UK \\ ${ }^{\mathrm{b}}$ Department of Physics, University of Manchester Institute of Science and Technology (UMIST), P. O. Box 88, \\ Manchester M60 1QD, UK \\ ${ }^{\mathrm{c}}$ Aerodyne Research, Inc., 45 Manning Road, Billerica, MA 01821, USA \\ ${ }^{\mathrm{d}}$ Department of Chemistry and CIRES, University of Colorado, Boulder, CO, USA \\ ${ }^{\mathrm{e}}$ Meteorological Service of Canada, 4905 Dufferin Street, Toronto, Ont., Canada, M3H 5T4
}

Received 16 July 2003; received in revised form 12 January 2004; accepted 19 January 2004

\begin{abstract}
Two Aerodyne Aerosol Mass Spectrometers (AMS) were deployed at three sites representing urban, semi-rural and rural areas during the Pacific 2001 experiment in the Lower Fraser Valley (LFV), British Columbia, Canada in August 2001. The AMS provides on-line quantitative measurements of the size and chemical composition of the non-refractory fraction of submicron aerosol particles. A significant accumulation mode with a peak around 400-500 nm was observed at all sites that was principally composed of sulphate, organics, ammonium and some nitrate. Another significant mode with a peak below $200 \mathrm{~nm}$ was also observed at the urban site and when urban plumes affected the other sites. This paper focuses on the variability of the organic particulate composition and size distribution as a function of location and photochemical activity with a particular emphasis on the urban and rural areas. The small organic mode at the urban site was well correlated with gas phase CO, 1,3-butadiene, benzene and toluene with Pearson's $r$ values of 0.76 , $0.71,0.79$ and 0.69 , respectively, suggesting that combustion-related emissions are likely to be the main source of the small organic mode at this site. The mass spectra of the urban organic particulate are similar to those of internal combustion engine lubricating oil, and of diesel exhaust aerosol particles, implying that they were composed of a mixture of $n$-alkanes, branched alkanes, cycloalkanes, and aromatics. In contrast, organic particulate at the rural site was dominated by shorter chain oxidized organic compounds. Correlations between the two organic modes and gas phase compounds at the rural site indicated that a significant part of the small mode originated from combustion sources, while the large accumulation organic mode appeared to be the result of photochemical processing. Processing
\end{abstract}

\footnotetext{
*Corresponding author. Current address: Department of Physics, University of Manchester Institute of Science and Technology (UMIST), P. O. Box 88, Manchester, UK; fax: + 44-161-2003951.

E-mail address: rami.alfarra@umist.ac.uk (M.R. Alfarra).
} 
of organic particulate during a relatively high $\mathrm{O}_{3}$ episode at the rural site appeared to increase the modal diameter of the accumulation mode from about 400 to $600 \mathrm{~nm}$ and almost doubled its mass loading.

(C) 2004 Elsevier Ltd. All rights reserved.

Keywords: Organic aerosols; Urban; Rural; Composition; Processing; Size distribution; Aerodyne aerosol mass spectrometer

\section{Introduction}

The importance of atmospheric particulate matter (PM) is becoming more widely recognized throughout the world because of its impact on global climate (Charlson et al., 1992), heterogeneous chemistry (Ravishankara, 1997), air quality (Fenger, 1999), and human health (Dockery et al., 1993; Brook et al., 2002; Pope et al., 2002). Understanding the composition of atmospheric aerosol particles is necessary for identifying their sources and predicting their effect on various atmospheric processes. Although organic compounds typically account for $10-70 \%$ of the total dry fine particle mass in the atmosphere (Gray et al., 1986; Middlebrook et al., 1998), organic PM concentrations, composition and formation mechanisms are not well understood, particularly in relation to the other major fine particle constituents, i.e. sulphate and nitrate compounds. This is because particulate organic matter is part of a complex atmospheric system with hundreds of different compounds, both natural and anthropogenic, covering a wide range of chemical and thermodynamic properties (Saxena and Hildemann, 1996). The presence of semi-volatile compounds complicates collection of organic PM. In addition, there is a current lack of a single analytical technique that is capable of analyzing the entire range of organics present.

Organic PM is both emitted directly in particulate form (primary organic aerosol particles) and formed in the atmosphere through photochemical oxidation of reactive organic gases forming low-volatility products that condense or adsorb onto particle surfaces, or absorb into pre-existing PM resulting in the addition of material to atmospheric particles; this process is known as "secondary organic aerosol particle formation". Under certain conditions atmospheric reaction products can nucleate to form new particles. Both biogenic and anthropogenic sources contribute to primary and secondary organic particulate (Hildemann et al., 1996). Secondary organic particulate can be a major contributor to fine particulate levels in both urban and rural atmospheres (Turpin and Huntzicker, 1995; Castro et al., 1999). However, the contributions of the primary and secondary components of particulate organic carbon (OC) have long been difficult to quantify. The lack of a direct chemical analysis method for the identification of either of these components has led researchers to employ several indirect methods.
These include the use of tracer compounds for either the primary or the secondary OC (Gray et al., 1986; Turpin and Huntzicker, 1991), the use of models describing the formation of secondary OC (Pandis et al., 1992) and the use of models describing the emission and dispersion of primary OC (Harley and Cass, 1995).

In August 2001, the Pacific 2001 field study was conducted in the Lower Fraser Valley (LFV), British Columbia, Canada in order to provide a better understanding of the sources, formation and distribution of PM and ozone in that area. The LFV has topographic features similar to that of the Los Angeles basin and experiences the interaction of urban, suburban, marine and agricultural emissions of pollutants and their subsequent transformation in ambient air ( $\mathrm{Li}$, this issue). The valley periodically experiences episodes of elevated levels of ozone and fine PM in the summer resulting in poor visibility and possible health effects. These episodes are typically experienced when the region is under the influence of synoptic high pressure systems that lead to subsidence inversions which trap the surface primary pollutants in a shallow boundary layer (Li et al., 1997). Specific goals of the Pacific 2001 study were to determine the horizontal and vertical distributions and physical and chemical characteristics of fine PM and ozone in order to identify the transition from an emission-dominated regime to a formation-controlled regime in the valley, and to identify the major physical and chemical processes and roles of biogenic and anthropogenic emissions in the secondary organic aerosol particles and ozone formation ( $\mathrm{Li}$, this issue). In this paper, we present results from two Aerodyne Aerosol Mass Spectrometers (AMS), which provide on line quantitative measurements of the chemical composition and size distributions of the non-refractory fraction of sub-micron ambient aerosol particles. Measurements were carried out at three different sites representing urban, semi-rural and rural areas in the LFV as part of the Pacific 2001 field study during August 2001. This paper presents the variability of the organic particulate composition and size distributions as a function of location and photochemical activity with a particular focus on the urban and rural areas. Correlations with gas phase marker compounds have been used to explain both sources and modal behaviour of organic particulate. Identification of organic ion series, as well as key mass fragments has been used in an attempt to further understand the chemical composition of the 
organic fraction of the aerosol particles. The companion paper (Boudries et al., this issue) provides a detailed comparison of the physical and chemical properties of aerosol particles measured at the three sites and uses meteorological back-trajectory analysis to determine the impact of various sources and atmospheric transport on the aerosol particles observed in the LFV.

\section{Experimental}

\subsection{Description of the Aerodyne AMS}

The AMS, developed by Aerodyne Research Inc., (Billerica, MA, USA), provides on-line quantitative measurements of the chemical composition and size distributions of the non-refractory fraction of submicron aerosol particles (approximately $\mathrm{PM}_{1.0}$ ). A brief description of the AMS and the principle of operation will be given here. A more detailed description of the instrument and its various calibrations is given in other publications (Jayne et al., 2000; Allan et al., 2003a; Jimenez et al., 2003a,b; Drewnick et al., 2004a).

A schematic of the AMS is shown in Fig. 1. The instrument consists of three differentially pumped chambers: an aerosol sampling chamber, a particle sizing chamber and an analysis chamber, separated by a skimmer and a channel aperture, respectively. An aerodynamic lens (Liu et al., 1995a,b; Zhang et al., 2002) is used to focus submicron particles into a narrow beam, which is aligned to pass through a skimmer, a chopper, the particle-sizing chamber $(39.5 \mathrm{~cm}$ length), an aperture, and finally impacts on a $550^{\circ} \mathrm{C}$ heated surface. After flash vaporization of the non-refractory (volatile and semi-volatile) particle components, the vapour is ionised using standard $70 \mathrm{eV}$ electron impaction. The resulting positive ions are analyzed using a quadrupole mass spectrometer (QMA 410, Balzers, Liechtenstein) and detected with a calibrated electron multiplier. The separation of the vaporization and ionization steps is crucial because it allows for the quantification of the ion signals obtained by the mass spectrometer. In typical field operation, the AMS alternates between two data acquisition modes: the "Time-of-flight" (ToF) mode and the "Mass Spec" (MS) mode (Jimenez et al., 2003a). In the ToF mode the quadrupole mass spectrometer is set to scan pre-selected fragment ions, which are known to be produced by certain chemical species. The mass of key chemical components can be resolved as a function of the vacuum aerodynamic diameter of the particles $\left(\mathrm{d} M / \mathrm{d} \log D_{\mathrm{va}}\right)$ by averaging the time resolved ion signals after chopping the particle beam with the mechanical chopper $(2 \%$ duty cycle) at the front of the second chamber. The difference between vacuum aerodynamic diameter, measured by the AMS in a free-molecular regime flow, and classical aerodynamic diameter, measured in a continuum regime flow, and their relationship with mobility diameter are discussed in Jimenez et al. (2003b). In the MS mode the averaged chemical composition of the non-refractory aerosol components is determined by scanning the full mass spectrum $(1-300 \mathrm{~m} / \mathrm{z}$ units) with the quadrupole mass spectrometer. The chemical composition of the aerosol particles ensemble is obtained in the MS mode without size resolved information. During the MS mode the chopper position is alternated between "beam blocked" and "beam open" every $5 \mathrm{~s}$, where the aerosol beam is either totally obstructed or allowed to pass. The difference of the signal at "beam open" and "beam blocked" positions is used to calculate the aerosol mass concentration. The AMS alternately measures in MS and ToF modes by moving a chopper in and out of the aerosol particle beam by a computer controlled servo. The instrument spends $20 \mathrm{~s}$ in MS mode before switching to ToF mode for a further $40 \mathrm{~s}$ before the cycle is repeated. Detailed descriptions of the data interpretation, calibration and error analysis techniques, are discussed in Allan et al. (2003a, 2004b), while

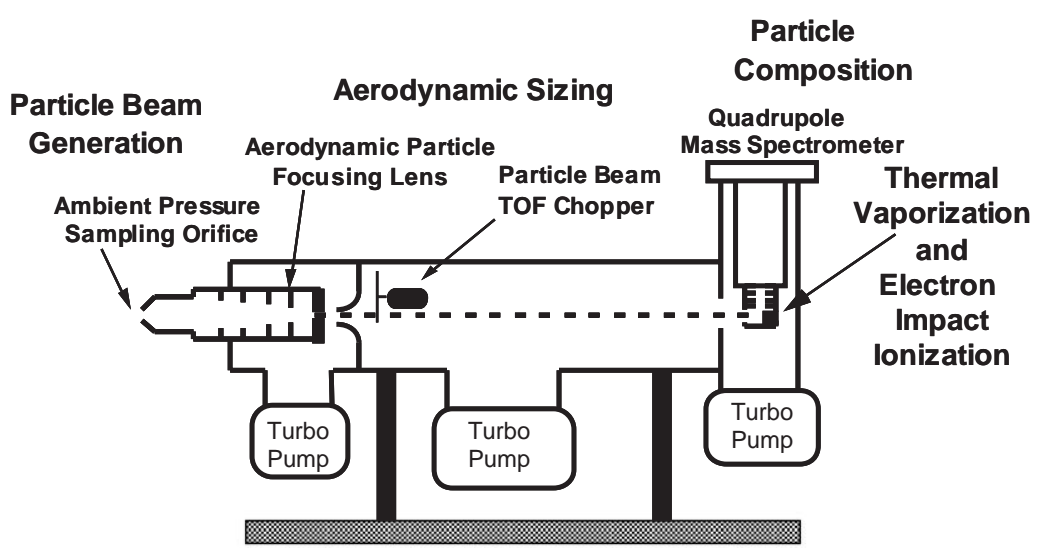

Fig. 1. A schematic of the Aerodyne AMS. 
identification and quantitative calibrations of chemical species are presented in Jimenez et al. (2003a). A method for calculating a total organic mass size distribution from a combination of the pre-selected ToF mass fragments and the ensemble MS was described in a previous publication (Allan et al., 2003b).

\subsection{Updated procedure for the calculation of AMS mass concentrations}

The quantification procedure for AMS mass concentrations has been revised with respect to that described previously (Allan et al., 2003a; Jimenez et al., 2003a). The mass concentration of a given species $\left(C_{\mathrm{s}}\right)$ was calculated using Eq. (6) of Jimenez et al. (2003a) as

$C_{\mathrm{s}}=R_{t} \frac{\sum_{f} I_{\mathrm{s} f}^{\text {corr }}}{N_{\mathrm{A}} Q} \frac{\mathrm{MW}_{\mathrm{NO}_{3}}}{\mathrm{IE}_{\mathrm{NO}_{3}}}$,

where $\sum I_{s f}^{\text {corr }}$ is the total ion current (in ions $\mathrm{s}^{-1}$ ) for all the ion fragments produced by a given species, $\mathrm{MW}_{\mathrm{NO} 3}$ is the molecular weight of nitrate $\left(62 \mathrm{~g} \mathrm{~mol}^{-1}\right), \mathrm{IE}_{\mathrm{NO} 3}$ is the measured ionization efficiency for nitrate, $N_{\mathrm{A}}$ is Avogadro's number and $Q$ is the air volume sampling rate into the AMS. $R_{t}$ is a response factor that takes into account the differences in ionization efficiency per unit mass for different species with respect to the measured $\mathrm{IE}_{\mathrm{NO} 3} / \mathrm{MW}_{\mathrm{NO} 3}$. $R_{t}$ is the inverse of the relative ionization efficiency per unit mass for species $s$, RIE ${ }_{s}$. In practice, the measured $\mathrm{IE}_{\mathrm{NO} 3}$ is determined only from the ion fragments $30\left(\mathrm{NO}^{+}\right)$and $46\left(\mathrm{NO}_{2}^{+}\right)$during calibration. Laboratory work has shown that these signals account for about $90 \%$ of the total nitrate ion signal for ammonium nitrate (Hogrefe et al., 2004). Thus $\mathrm{RIE}_{\mathrm{s}}$ also accounts for this difference between the true $\mathrm{IE}_{\mathrm{NO} 3}$ and the measured $\mathrm{IE}_{\mathrm{NO} 3}$.

Eq. (1) requires that the ion signals produced by a given species at all $m / z$ peaks are known. In some experiments, however, the contribution of a species to certain peaks in the mass spectrum cannot be directly measured due to overwhelming interference from other ions detected at the same $m / z$, such as the $\mathrm{S}^{+}$peak $(m / z$ 32) in the sulphate spectrum, which is dwarfed by the $\mathrm{O}_{2}^{+}$peak from gas phase oxygen when sampling in air. The Igor-based AMS analysis software package described by Allan et al. (2003a, 2004b) attempts to account for the non-measurable $m / z$ peaks for each species by using ratios derived from laboratory calibrations (Hogrefe et al., 2004) to estimate the peaks that cannot be measured (such as $m / z 32$ arising from the vaporization/ ionization of sulphate). Eq. (1) can be rewritten as

$C_{\mathrm{s}}=R_{t} C_{\mathrm{s}}^{\mathrm{eq}}$,

where $C_{\mathrm{s}}^{\mathrm{eq}}$ is known as the nitrate-equivalent mass concentration of the species, i.e. the mass of nitrate that would produce an ion current equivalent to that detected for species s (Jimenez et al., 2003a). However it has been observed that the direct application of Eqs. (1)-(2) underestimates the aerosol sulphate mass concentrations when comparing AMS data to data from other colocated instruments by a factor of 2 (Drewnick et al., 2003). Drewnick et al. state that part of this discrepancy arises from differences in the particle size cuts for the colocated instruments. Based on several additional laboratory and field tests (Allan et al., 2004a), we believe that a significant fraction of the observed underestimation is due to the fact that some ambient particles are irregular in shape and a fraction of them do not reach the vapourizer due to the known lower focusing efficiency of the aerodynamic lens inlet for nonspherical particles (Liu et al., 1995b; Jayne et al., 2000; Kane and Johnston, 2000; Tobias and Ziemann, 2000). To characterise this effect, we define the particle collection efficiency, $\mathrm{CE}_{\mathrm{s}}$, as the fraction of the sampled particle mass of a given species that reaches the AMS detector (e.g. $\mathrm{CE}_{\text {sulphate }}=50 \%$ ). From a physical point of view, $\mathrm{CE}_{\mathrm{s}}$ should actually be defined for particles and not species, and in principle could be a function of particle size for particles of the same composition and physical shape. To take into account this effect, we rewrite Eq. (2) above as

$C_{\mathrm{s}}=R_{t}^{\prime} C_{\mathrm{s}}^{\mathrm{eq}}$,

where the only change is the replacement of $R_{t}$ by $R_{t}^{\prime}$ in order to include the particle collection efficiency, $\mathrm{CE}_{\mathrm{s}}$. $R_{t}^{\prime}$ is then defined as

$R_{t}^{\prime}=\frac{1}{\mathrm{RIE}_{\mathrm{s}} \mathrm{CE}_{\mathrm{s}}}=R_{t} \frac{1}{\mathrm{CE}_{\mathrm{s}}}$.

The $\mathrm{CE}_{\mathrm{s}}$ and $\mathrm{RIE}_{\mathrm{s}}$ factors used here are shown in Table 1 for each species. The RIE values in the table have been determined from laboratory calibrations with particles of each species. Note that no ammonium data are presented here. However, these same $\mathrm{CE}_{\mathrm{s}}$ and $\mathrm{RIE}_{\mathrm{s}}$

Table 1

The relative ionization efficiencies with respect to the value of $\mathrm{IE}_{\mathrm{NO} 3}$ obtained by using only the ion fragments $30\left(\mathrm{NO}^{+}\right)$and $46\left(\mathrm{NO}_{2}^{+}\right)$and the collection efficiencies for each species at Langley and Slocan Park sites.

\begin{tabular}{llll}
\hline Chemical species (s) & $\mathrm{RIE}_{\mathrm{s}}$ & $\begin{array}{l}\mathrm{CE}_{\mathrm{s}} \\
\text { (Langley) }\end{array}$ & $\begin{array}{l}\mathrm{CE}_{\mathrm{s}} \\
\text { (Slocan Park) }\end{array}$ \\
\hline Nitrate & 1.1 & 1.0 & 0.5 \\
Ammonium & 3.5 & 1.0 & 0.5 \\
Sulphate & 1.15 & 1.0 & 0.5 \\
Organics & 1.4 & 1.0 & 0.5 \\
\hline
\end{tabular}

Note that the RIE $\mathrm{NO}_{3}$ accounts for the difference between the measured and true IE of ammonium nitrate. 
factors were used in the accompanying paper (Boudries et al., this issue) where ammonium data are presented.

A $\mathrm{CE}_{\mathrm{s}}$ of $50 \%$ has been used in this paper for all species at Slocan Park. Previous field studies (Drewnick et al., 2003) have shown that particle mass is underestimated by the AMS for ammonium sulphate dominated aerosol by a factor of 2 (i.e. $\mathrm{CE}_{\text {sulphate }}=50 \%$ ). Allan et al. (2004a) found that if the sampled aerosol flow into the inlet of the instrument is maintained at a high relative humidity, the mass of all the accumulation mode species increases by approximately a factor of 2 . This implies that the ammonium sulphate effloresces at lower RH causing the particles to become non-spherical, dropping the $\mathrm{CE}_{\text {sulphate }}$ to approximately $50 \%$. Thus, $\mathrm{CE}_{\mathrm{S}}$ is a function of particle composition and the relative humidity within the inlet, which is dependent on the ambient water vapour concentration and temperature, and the temperature of the laboratory. Since the accumulation mode aerosol at Slocan contained a significant amount of ammonium sulphate mass and the sampling relative humidity was consistently low, a $\mathrm{CE}_{\text {sulphate }}=50 \%$ is used. This work and previous studies (Allan et al., 2003b) provide indirect evidence that the organic and inorganic components in the accumulation mode are internally mixed based on the similar temporal variability and shape of their modes. It is therefore reasonable to assume a $\mathrm{CE}$ of $50 \%$ for accumulation mode nitrate and organics. To date, there are no studies to determine the $\mathrm{CE}$ of the organic material in the small organic mode. Since these organic particles are known to have irregular shapes (Weingartner et al., 1997), it is probable that they will not be totally focused through the aerodynamic lens and as a result may have a CE less than $100 \%$. We assume a CE of $50 \%$ for the small organic particles in this study. Current experiments to analyse the beam shape are underway to investigate the validity of this assumption for future experiments, and to study other aspects of the AMS calibrations. Clearly two AMS instruments operating in different laboratories at different temperatures may have different values of $\mathrm{CE}_{\mathrm{s}}$. This was the case in Pacific 2001, the temperature control in the Slocan Park cabin was poor and often the sampling inlet temperature was higher than ambient (RH low), while the cabin at Langley was well air conditioned ( $T_{\text {sample }}<T_{\text {ambient }}$; RH high). The low RH sampling of ammonium sulphate dominated aerosol at Langley taken together with the observations of Allan et al. (2004a) leads to the use of a $\mathrm{CE}_{\mathrm{s}}$ of $100 \%$ for all species at Langley (Boudries et al., this issue).

The AMS results were compared to other independent methods of PM measurement (MOUDI and TEOM) (K. Anlauf and J. Brook, personal communications, Environment Canada, Toronto, Canada) at both sites and produced excellent correlations at both sites. However, the TEOM and MOUDI reported higher absolute mass concentrations relative to the AMS, particularly at
Slocan Park. The comparisons between the AMS and MOUDI mass size distributions for $\mathrm{PM}_{1.0}$ indicate that the discrepancy in total mass between the AMS and the other instruments is likely due to the difference in size cuts between the $\mathrm{PM}_{1.0}$ AMS and the other $\mathrm{PM}_{2.5}$ instruments.

\subsection{Field sites and AMS sampling}

This section provides a brief description of the AMS deployment sites and sampling protocols. More details about the Pacific 2001 sampling sites and AMS deployments and sampling protocols can be found in $\mathrm{Li}$ (this issue) and Boudries et al. (this issue), respectively. Two Aerodyne AMS were operated at three main field sites during the Pacific 2001 experiment in the LFV, British Columbia, Canada during the summer of 2001. The Slocan Park site was located in the city of Vancouver and represented a background urban location, where a mixture of primary and secondary PM was expected. The site was surrounded by $2-3$ storied residential houses situated at least $80 \mathrm{~m}$ away from the sampling location. There were no major point sources within a radius of $3 \mathrm{~km}$ of the site. Traffic in the nearby streets was typically light. The first AMS was deployed at this site from 12 to 24 August 2001. Sampling was carried out through a $\mathrm{PM}_{2.5}$ cyclone inlet about $2 \mathrm{~m}$ above the trailer roof using $8 \mathrm{~m}$ of $0.5 \mathrm{inch}(1.27 \mathrm{~cm})$ O.D. copper tubing, at a flow rate of $101 \mathrm{~min}^{-1}$. The Langley site was selected to study the transition from an urban to rural setting, and to characterize particles arising form agricultural activities. It was located in the middle of agricultural fields to the southeast of the city of Vancouver with no nearby major residential houses or traffic. The second AMS was deployed at this site for the duration of the field study from 12 August to 01 September 2001. Ambient sampling was carried out using the same inlet system as the one described above for the Slocan Park site. The Sumas mountain site was located on the eastern side of the valley. It was chosen to address the interaction between aging urban pollution and biogenic emissions resulting from the coniferous tree covered slopes of the mountain. Results from the latter site are not discussed in this paper, and the reader is referred to Boudries et al. (this issue) for details.

\section{Results and discussion}

\subsection{Overview of chemical composition and size distributions}

Mass size distributions of the sulphate, nitrate and organic fractions of the aerosol particles at Slocan Park and Langley sites averaged over the whole sampling period at the Slocan Park site are shown in Fig. 2. It is 

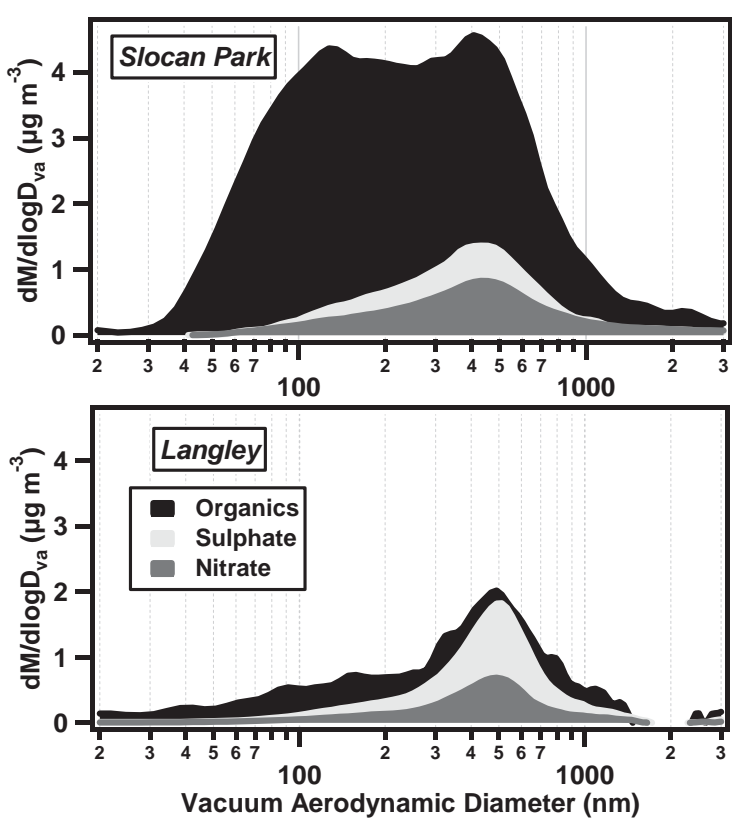

Fig. 2. Size distributions of organics, sulphate and nitrate measured at Slocan Park (top panel) and Langley (bottom panel) averaged over the sampling duration at Slocan park. Loadings of individual components are overlaid.

important to note that these averages are for long periods and they do not show the temporal variability of the particle size distribution, chemical composition and mass concentration. They do, however, provide an overview of the behaviour of the particles at Slocan Park and Langley during the Pacific 2001 experiment over the specified measurement period. A significant accumulation mode with vacuum aerodynamic diameters around $300-700 \mathrm{~nm}$, and peaking around $400-500 \mathrm{~nm}$ was observed at both sites and was principally composed of sulphate, organic material and some nitrate. Though not shown in the figure, the ammonium distribution is similar to that of both sulphate and nitrate. The temporal variations of the size distributions of the accumulation mode components suggest that they are internally mixed and are indicative of a regional background mode. A significant mass mode at a vacuum aerodynamic diameter of about $100-200 \mathrm{~nm}$ was constantly observed at Slocan Park and when urban air masses affected the Langley site Boudries et al. (this issue). This mode was principally composed of organic material with very small concentrations of inorganic species. This finding is consistent with previous observations made at other urban sites in the UK and the US (Jimenez et al., 2003a; Allan et al., 2003b; Drewnick et al., 2004b). The small organic mode appears to be characteristic of urban sites and fresh emissions. At Langley, the measurements were often made away from local sources and the small mode became less significant and the distribution was dominated by the accumulation mode. The disappearance of the small organic mode as the air masses are advected away from urban areas is most likely due to a combination of the effect of coagulation, condensation (which would result in particle growth) and dry deposition.

\subsection{Urban organic particulate}

Organic particulate shows a consistent bimodal size distribution at the urban site of Slocan Park. The accumulation mass mode peaks at around $450 \mathrm{~nm}$, while the peak of the smaller mode occurs below $150 \mathrm{~nm}$. In order to determine the sources of the particulate in the two modes, they were treated separately by fitting two log normal distributions to the organic size distribution data set using a Levenberg-Marquardt non-linear least squares fit (Press, 1992). The area under each fitted mode represents its total organic mass loading. The small organic mode mass loading was significant at the Slocan urban site almost all of the time, while it was observed only during some periods at the rural site of Langley; suggesting that this mode originated from urban sources (Boudries et al., this issue). During periods where $\mathrm{CO}$ and 1,3-butadiene concentrations were high, the small organic mass mode was clearly enhanced. Fig. 3 shows strong positive correlations between the small organic mode mass loading with $\mathrm{CO}$ and 1,3-butadiene concentrations. These correlations had Pearson's $r$ values of 0.76 and 0.71 , respectively. Similar correlations were also calculated for benzene and toluene and resulted in Pearson's $r$ values of 0.79 and 0.69 , respectively. These gas phase compounds are good markers of transport-related emissions and were themselves well correlated within this experiment, with a Pearson's $r$ value of 0.75 for $\mathrm{CO}$ and 1,3-butadiene. The major source of these trace gases in urban environments is from motor vehicle exhaust (GVRD, 2002), and the strong correlation suggests that combustion-related emissions (with traffic likely representing a large fraction) are the main source of the small organic mode at Slocan Park urban site. This is consistent with many other studies including our previous urban measurements in two major UK cities (Allan et al., 2003b)

Experiments performed in our laboratories have shown that mass spectra obtained using the AMS compare well to the NIST standard library of mass spectra for a range of chemical compounds with the exception of di- and poly carboxylic acids and humiclike substances, where $m / z 44\left(\mathrm{CO}_{2}^{+}\right)$was found to be much more pronounced in the AMS spectra. The enhanced $m / z 44$ signal was coupled with a very strong peak at $m / z 18$ indicative of $\mathrm{H}_{2} \mathrm{O}^{+}$, implying thermal breakdown of the carboxylic acid group on the vaporizer. This phenomenon is reproducible and, 

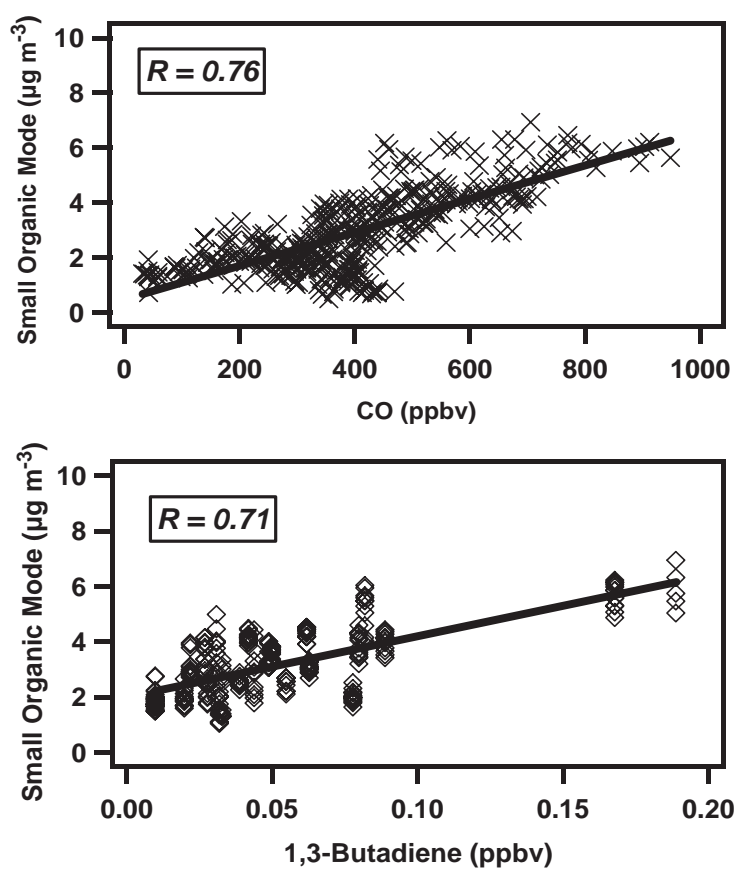

Fig. 3. The small organic mode mass loading plotted against gas phase $\mathrm{CO}$ (top panel) and 1,3-butadiene (bottom panel) concentrations and best fitted lines for the sampling duration at Slocan Park.

coupled with the fact that $m / z 44$ is generally small when sampling primary aerosol materials such as hydrocarbons, allows us to use this peak as an indicator of oxidized organic compounds measured by the AMS. The $m / z 43$ is a characteristic fragment of both saturated hydrocarbon compounds $\left(\mathrm{C}_{3} \mathrm{H}_{7}^{+}\right)$and oxidized organic compounds such as aldehydes and ketones $\left(\mathrm{CH}_{2} \mathrm{CHO}^{+}\right.$ or $\mathrm{CH}_{3} \mathrm{CO}^{+}$). On the other hand $\mathrm{m} / z 57$ is a typical fragment of saturated hydrocarbon compounds $\left(\mathrm{C}_{4} \mathrm{H}_{9}^{+}\right)$ and gets a negligible contribution from oxidized organic compounds. Fig. 4 shows the size distributions of those three key organic mass fragments, in addition to the total organic fraction, averaged over the whole sampling period at the Slocan Park site. The $m / z 44$ fragment shows a pronounced mostly mono modal distribution, with a modal diameter of about $450 \mathrm{~nm}$. This implies that there is little contribution from highly oxidized organic compounds in the small organic mode. The other two mass fragments $(m / z 43$ and 57) show bimodal mass size distributions similar to that observed for the total organic aerosol fraction. It is important to note that the two modes of $\mathrm{m} / \mathrm{z} 43$ have similar peak magnitudes, while the accumulation mode is smaller than the small mode in the case of $m / z 57$ indicating that oxidized species contribute more to $m / z 43$ than $m / z 57$ in the accumulation mode size range.

Panel A in Fig. 5 shows a mass spectrum of diesel bus exhaust aerosol obtained by Canagaratna et al. (2004) in

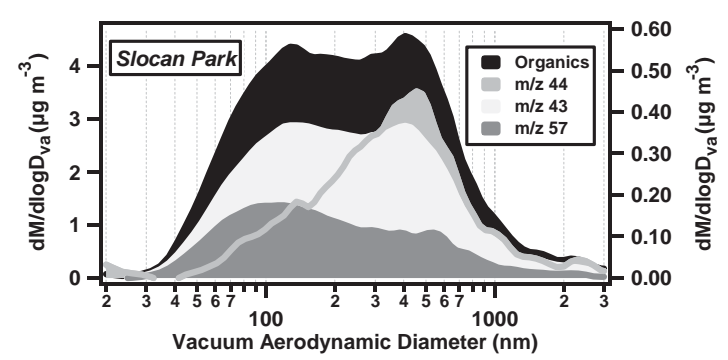

Fig. 4. Size distributions of selected organic mass fragments (right axis), together with the total organic size distribution (left axis) averaged over the sampling duration at Slocan Park. Loadings of individual components are overlaid.
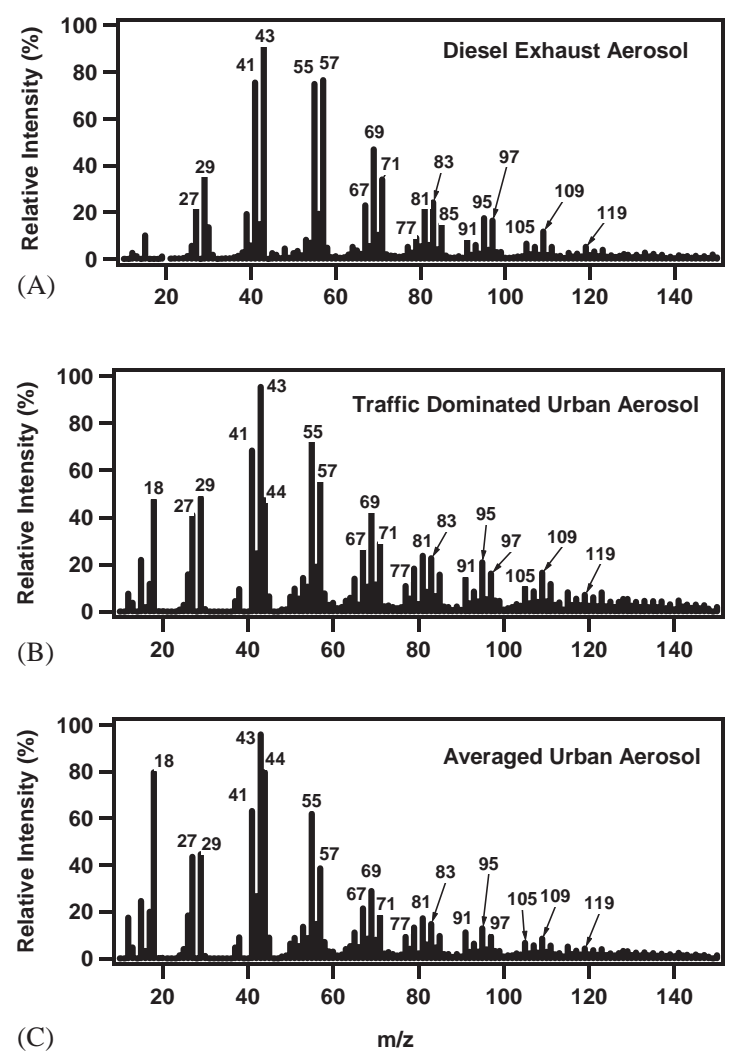

Fig. 5. AMS mass spectra obtained from (A) diesel bus exhaust during a vehicle chasing study in NYC, (B) ambient organic particulate at Slocan Park averaged over periods dominated by traffic emissions where $\mathrm{CO}$ concentrations were higher than the local mean value of 403 ppbv, and (C) ambient urban organic particulate averaged over the sampling duration at Slocan Park.

a recent "vehicle chasing" study using an AMS instrument identical to the one used here. The study was designed to characterize both gaseous and PM emissions from individual in-use vehicles under real world driving conditions in New York City. The diesel exhaust spectrum was compared to laboratory generated 
diesel fuel and lubricating oil spectra and the study concluded that under most operating conditions the organic carbon fraction of in-use diesel vehicle exhaust aerosol is dominated by the recondensed vapour from the evaporated engine lubricating oil. These findings were similar to those found by Tobias et al. (2001), which concluded that the dominant organic components of fuel and lubricating oil are $n$-alkanes, branched alkanes, cycloalkanes, and aromatics (including polyaromatic hydrocarbons). All spectra were dominated by the ion series $\mathrm{C}_{n} \mathrm{H}_{2 n+1}^{+}(m / z 29,43,57,71,85, \ldots)$, which is typical of saturated normal and branched alkanes. Other important ion series were also observed including $\mathrm{C}_{n} \mathrm{H}_{2 n-1}^{+}(m / z 27,41,55,69,83, \ldots)$ typical of alkenes, $\mathrm{C}_{n} \mathrm{H}_{2 n-3}^{+}(m / z 67,79,81,95,107,109, \ldots)$ typical of cycloalkanes and $\mathrm{C}_{6} \mathrm{H}_{5} \mathrm{C}_{\mathrm{n}} \mathrm{H}_{2 \mathrm{n}}^{+}(\mathrm{m} / z \mathrm{z} 77,91,105,119, \ldots)$ typical of aromatics (McLafferty and Turecek, 1993). Panel B in Fig. 5 shows a mass spectrum of the organic fraction of the ambient particles obtained at the Slocan Park urban site during periods dominated by traffic emissions. The spectrum is an average of the organic particulate composition during all periods where $\mathrm{CO}$ concentrations were higher than the local average (403 ppb). Panel C in Fig. 5 is an averaged spectrum of the ambient urban organic particulate composition at Slocan Park across the entire sampling period. The organic mass spectra from the AMS are derived using a method designed to separate the ensemble mass spectra obtained by the instrument into partial mass spectra for distinct chemical species (Allan et al., 2004b). A comparison of the ambient organic mass spectra in panels B and C with that of the diesel exhaust in Panel A suggests a significant similarity between the composition of the traffic-dominated ambient organic particulate in Vancouver and that of diesel exhaust organic particulate in New York City. The main differences are that the ambient spectra show an extra fragment at $m / z 44$ coupled with a fragment at $m / z 18$, a relatively more enhanced $m / z 43$ relative to its adjacent fragments and a more abundant $\mathrm{m} / \mathrm{z} 55$ relative to $\mathrm{m} / \mathrm{z} 57$. Oxidized organic compounds contributing to the accumulation mode are likely to be the sources of these subtle differences. A comparison between the spectra in Panels $\mathrm{B}$ and $\mathrm{C}$ in Fig. 5 strongly suggests that compounds related to traffic emissions largely dominate the averaged composition of ambient urban organic particulate, although it is possible that other sources could produce similar mass spectra.

A bimodal size distribution with a significant combustion-related small organic mode composed of hydrocarbons and aromatics was found to be typical of the Slocan Park urban site. However, during the first few days of the experiment the site was exposed to a photochemical episode where the $\mathrm{O}_{3}$ level reached $\sim 80 \mathrm{ppbv}$ at times. Fig. 6 shows an averaged organic mass size distribution and mass spectrum averaged over all periods where $\mathrm{O}_{3}$ concentrations exceeded $50 \mathrm{ppbv}$ at Slocan Park. In contrast to the average organic size distribution across the whole experiment shown in Fig. 2, the organic distribution in Fig. 6 shows that during this period of intensive photochemistry the accumulation mode was significantly enhanced and dominated the distribution with a mass loading almost twice its average value. The mass spectrum in Fig. 6 represents the averaged chemical composition of the organic particulate during these periods. The most significant features of this spectrum are the high abundance of $\mathrm{m} / \mathrm{z} 44$ coupled with $\mathrm{m} / \mathrm{z} 18$ in addition to the high ratio of $\mathrm{m} / \mathrm{z} 55$ relative to 57 ; both are characteristic of oxidized organic compounds. Other hydrocarbon and aromatic-related ion series can still be observed, as their combustion-related sources always exist at this urban site.

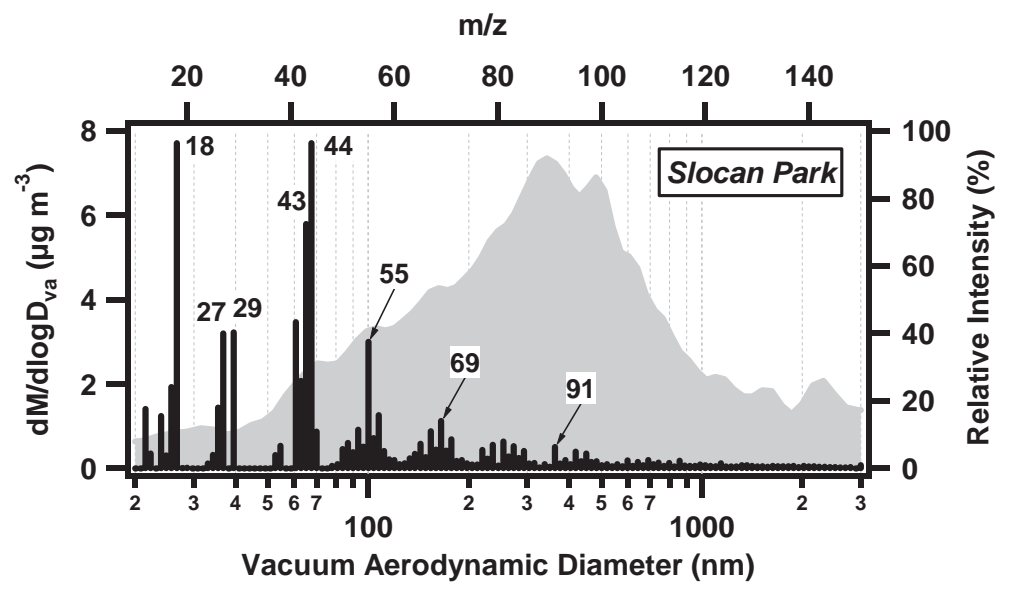

Fig. 6. Size distribution and mass spectrum of ambient organic particulate averaged over all periods where $\mathrm{O}_{3}$ concentrations exceeded 50 ppbv at Slocan Park. 


\subsection{Rural organic particulate}

The averaged size distribution of the organic fraction at the Langley rural site is clearly different from that at Slocan Park, (Fig. 2). It is dominated by an accumulation mode with a peak around $450 \mathrm{~nm}$, in addition to a smaller, broad mode below $200 \mathrm{~nm}$. This is consistent with the site being rural with fewer sources of fresh emissions as compared to urban areas. Fig. 7 shows mass size distributions of the three key organic mass fragments described in Fig. 4, in addition to that of the total organic fraction, averaged across the sampling duration at Langley. The dominance of mass fragments 44 and 43 in the accumulation mode and the lack of significant contributions from mass fragments 57 and 43 in the small mode suggest that organic particulate at this rural site has a large contribution from oxidized compounds (secondary organic aerosol). This is further confirmed in Fig. 8, which shows an averaged mass spectrum of the organic aerosol fraction at Langley across the duration of the experiment, including periods where the site was exposed to fresh air masses. The biggest contributions to this spectrum come from mass fragments characteristic of oxidized organic compounds such as $m / z 44$ coupled with $m / z 18$ in addition to mass fragments 43 and 55 . The spectrum also shows small contributions from fragments typical of aromatic and cyclic compounds such as 67, 79, 91, 95 and 105.

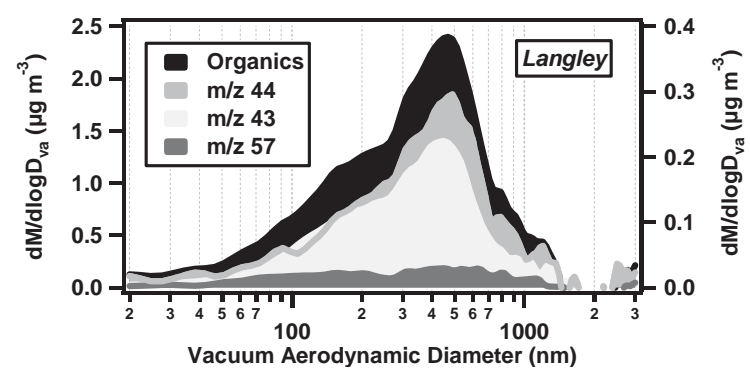

Fig. 7. Size distributions of selected organic mass fragments (right axis), together with the total organic size distribution (left axis) averaged over the sampling duration at the Langley site. Loadings of individual components are overlaid.

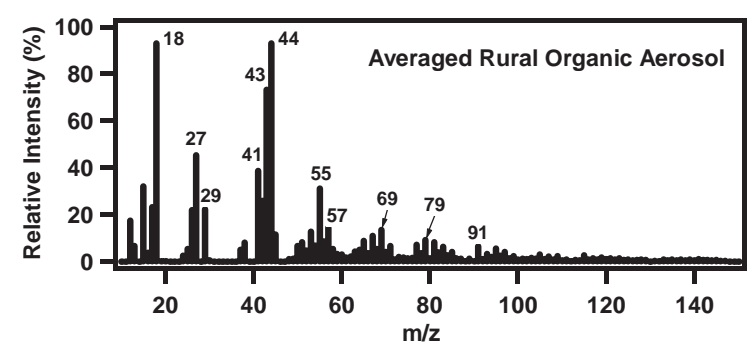

Fig. 8. A mass spectrum of organic particulate averaged over the sampling duration at Langley site.
Similar to the analysis applied to the Slocan Park data, two log normal distributions were fitted to the Langley data in an attempt to understand the behaviour of the two organic modes. However, as the two modes were typically less distinct than at Slocan Park, the fits converged less often and the fitted parameters had to be treated carefully. Any fitted distributions that did not result in a turning point between the two peaks were treated as mono modal and the fit was rejected. The total mass loading of each mode was compared with the concentration of the gas phase species $\mathrm{CO}, \mathrm{NO}, \mathrm{SO}_{2}, \mathrm{O}_{3}$, peroxyacetyl nitrate (PAN), and $\mathrm{NO}_{\mathrm{y}}$; the total sum of oxidized nitrogen-containing compounds using the method introduced by Allan et al. (2004a). The correlations were quantified using Pearson's $r$ values as illustrated in Fig. 9, and were calculated for the whole AMS sampling period at Langley from 11 August to 01 September 2001. Gas phase data were available for most species at most times except for $\mathrm{NO}$ and $\mathrm{NO}_{y}$, for which there were no data between the 21 and 26 August. In addition there were no $\mathrm{CO}$ data available between 17 and 21 August. The small organic mode had the strongest correlations with $\mathrm{CO}$ and $\mathrm{NO}_{y}$ (which includes $\mathrm{NO}_{x}$ ) indicating that a significant part of this mode originated from combustion sources; similar to that found at the Slocan Park site. On the other hand, the large accumulation organic mode had the strongest correlations with PAN and $\mathrm{O}_{3}$, which are indicators of photochemical oxidation and production, respectively. The correlations in Fig. 9 combined with the size distributions in Fig. 7 suggest that the small organic mode was mainly observed when the Langley site was
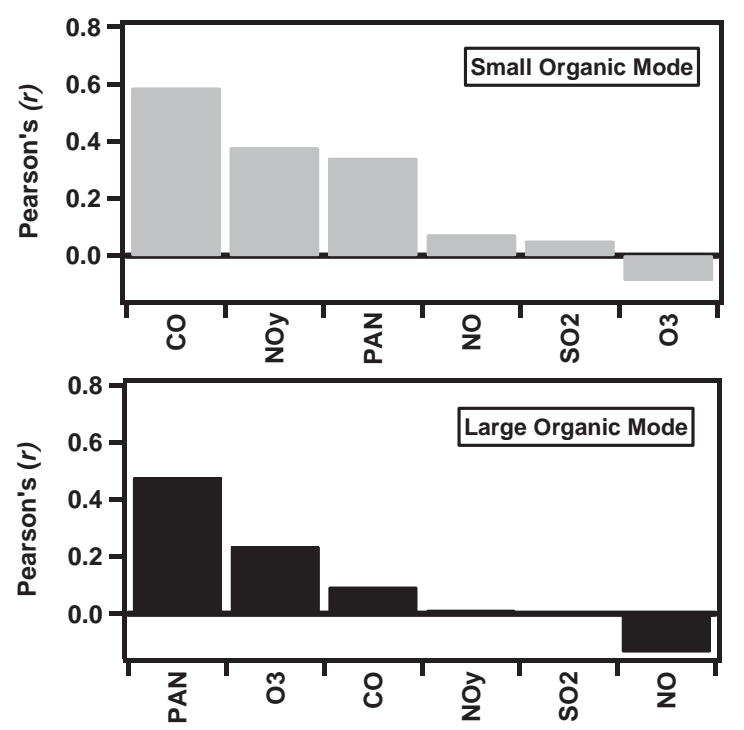

Fig. 9. Correlations between various gas phase compounds with the small organic mode loading (top panel) and the large organic mode loading (bottom panel) at the Langley site. 
exposed to recent combustion emissions, while a large fraction of the accumulation mode was a result of secondary aerosol formation and/or aerosol photochemical processing.

\subsection{Processing of organic particulate}

The graphs in Fig. 10 classify organic particulate measured at urban locations in Manchester, UK (Allan et al., 2003b) (Panel A), Slocan Park, Canada (Panel B) and at a rural location in Langley, Canada (Panels $\mathrm{C}$ and $\mathrm{D}$ ) as a function of the $\mathrm{CO}$ and $\mathrm{O}_{3}$ concentrations observed at these locations during the same measurement periods. Each panel (A-D) shows two organic mass size distributions averaged over conditionally selected periods. The selection criteria for the first distribution in panels $(\mathrm{A}-\mathrm{C})$ are that $\mathrm{CO}$ concentrations are higher than the local mean value and $\mathrm{O}_{3}$ concentrations are lower than the local mean value (hereafter referred to as $\mathrm{HC}$ and $\mathrm{LO}$ ). The second distribution in panels $(\mathrm{A}-\mathrm{C})$ has the converse criteria of $\mathrm{HO}$ and $\mathrm{LC}$ applied. Table 2 shows the local mean concentrations of $\mathrm{CO}$ and $\mathrm{O}_{3}$ at each site. The $\mathrm{HC}$ and $\mathrm{LO}$ periods indicate a higher than average influence of combustion-related emissions and lower than average secondary oxidant availability, while the $\mathrm{HO}$ and LC periods discriminate in favour of periods of opposite conditions. The averages over the $\mathrm{HC}$ and LO periods should therefore represent periods when the small organic mode is enhanced and the averages over the HO and LC periods should reflect increased secondary aerosol formation. At Slocan Park and in Manchester the organic mass loading is considerably higher during the $\mathrm{HC}$ and $\mathrm{LO}$ periods relative to the $\mathrm{HO}$ and $\mathrm{LC}$ periods. This is largely a function of mixing. During stable, poorly mixed conditions, the emissions of $\mathrm{CO}$, particles and $\mathrm{NO}$ are elevated, the latter titrating the available $\mathrm{O}_{3}$. During well-mixed periods dilution significantly reduces the concentration of the emitted species and regional $\mathrm{O}_{3}$ is entrained into the city. At the rural site, $\mathrm{O}_{3}$ and other secondary oxidants have had time in the atmosphere to form and are often elevated, whereas the influence of urban sources is intermittent and dependent on the synoptic meteorology at the time. The latter is reflected in the highly variable $\mathrm{CO}$ concentrations observed. Also shown in panels $(\mathrm{A}-\mathrm{C})$ are the mass spectral fingerprints obtained in these contrasting situations. The average mass spectra acquired during the $\mathrm{HC}$ and $\mathrm{LO}$ periods are shown for the urban experiments in panels $\mathrm{A}$ and $\mathrm{B}$ and that acquired during the $\mathrm{HO}$ and $\mathrm{LC}$ periods is shown in panel $\mathrm{C}$.

The figure shows that organic aerosols had bimodal size distributions during the $\mathrm{HC}$ and $\mathrm{LO}$ periods at urban locations (A, B), as discussed in Section 3.2. During HO and LC periods a much more significant accumulation mode relative to the small mode was observed. On the other hand, the organic size distribution at the rural site, panel $\mathrm{C}$, shows a dominant accumulation mode relative to a broad and less defined smaller mode in both conditionally averaged cases. However, a comparison of the organic distribution during $\mathrm{HC}$ and $\mathrm{LO}$ periods to that of $\mathrm{HO}$ and $\mathrm{LC}$ periods shows that the former has a broader small organic mode suggesting more fresh emissions during the $\mathrm{HC}$ and LO periods into a background of a large mass of accumulation mode oxidized organic aerosol. The organic mass spectra during the $\mathrm{HC}$ and LO periods at both urban locations seem to have almost the same fragments; indicating that the chemical composition of the recently emitted organic particulate in Manchester and Vancouver is likely to be very similar, which, when compared with laboratory generated mass spectral signatures (discussed in Section 3.2), implies a mixture of saturated and un-saturated hydrocarbons, cyclic compounds and some aromatics. The mass spectrum in panel $\mathrm{C}$ shows the averaged chemical composition of organic particulate during $\mathrm{HO}$ and LC periods at the rural site. The spectrum looks clearly different to those of the fresh urban aerosols in graphs A and B. It is dominated by mass fragments that are typical of oxidized organic compounds such as $\mathrm{m} / \mathrm{z} 44$ coupled with $m / z 18$, signatures of di- and polycarboxylic acids, in addition to mass fragments 43 and 55 which can be associated with other types of oxidized organic compounds including aldehydes and ketones (McLafferty and Turecek, 1993). The hydrocarbon contribution to mass fragments 43 and 55 is likely to be small in this spectrum as the signal at $m / z 57$ is almost negligible and the small organic mode is negligibly small during the $\mathrm{HO}$ and LC periods. The spectrum also contains very small contributions from mass fragments typical of cyclic compounds such as $m / z \quad 67$ and 79 in addition to aromatic fragments like $m / z$ 91. The presence of relatively high molecular weight fragments in the urban spectra represents another significant difference between the rural and urban organic particulate, suggesting that secondary organic aerosols or the processed primary organic compounds produce shorter carbon chain fragments. The rate of this transformation will be enhanced during periods of enhanced $\mathrm{O}_{3}$ concentrations when oxidant availability is high. However, as the site experienced a range of different air masses it is not possible to definitely conclude that the spectrum in graph $\mathrm{C}$ is a result of processing of recently emitted (urban-like) organic aerosols and rule out any other possible rural sources.

Panel D in Fig. 10 shows two organic size distributions averaged over periods where $\mathrm{CO}$ and $\mathrm{O}_{3}$ concentrations observed at the rural site in Langley were highly elevated relative to their measured mean values at this site. The distributions were obtained by selecting data only when the $\mathrm{CO}$ concentrations were higher than 

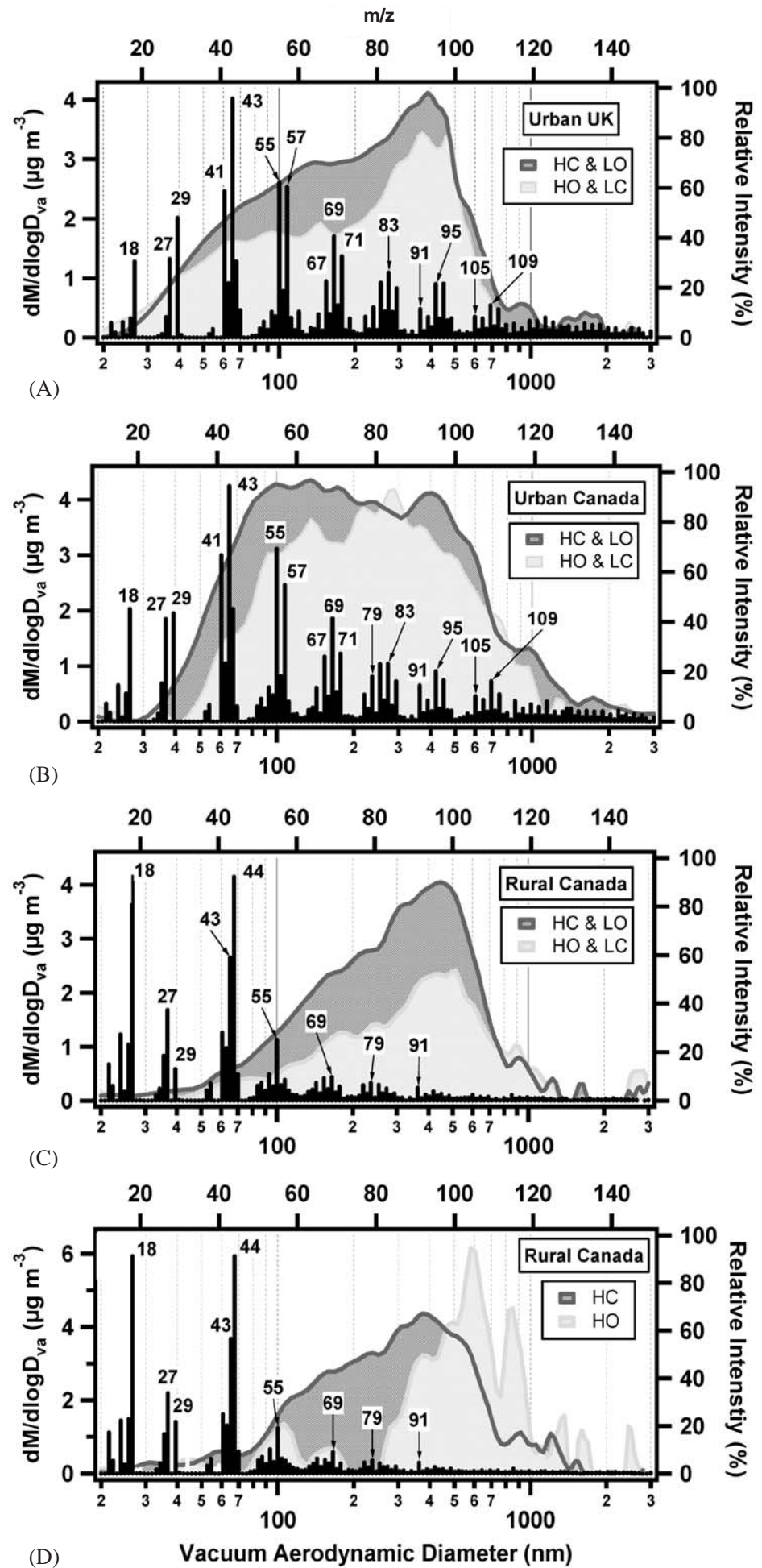

Fig. 10. Mass size distributions of organic particulate conditionally averaged (see text). The data shown are for urban locations in Manchester, UK (Panel A), Slocan Park, Canada (Panel B) and rural Canada (Panel C). The average organic mass spectra acquired during $\mathrm{HC}$ and $\mathrm{LO}$ (high $\mathrm{CO}$ and low $\mathrm{O}_{3}$ respectively, see text for details) periods are shown for the urban locations (Panels A and $\mathrm{B}$ ) and that acquired during $\mathrm{HO}$ and LC periods is shown for the rural location (Panel C). Organic mass size distribution and mass spectrum averaged over relatively elevated concentrations of $\mathrm{CO}$ and $\mathrm{O}_{3}$ at the rural site are shown (Panel D). The organic distributions averaged during $\mathrm{HO}$ and LC periods in Panels A and B have been multiplied by 3 and 2, respectively, for clarity. 
Table 2

Local mean concentrations of $\mathrm{O}_{3}$ and $\mathrm{CO}$ used in the conditional averaging of organic size distributions in Fig. 10

\begin{tabular}{lll}
\hline Location & $\begin{array}{l}\mathrm{O}_{3} \text { mean } \\
\text { concentration } \\
\text { (ppbv) }\end{array}$ & $\begin{array}{l}\text { CO mean } \\
\text { concentration } \\
\text { (ppbv) }\end{array}$ \\
\hline $\begin{array}{l}\text { Manchester, UK } \\
\text { Slocan Park, }\end{array}$ & 12 & 289 \\
Canada & 18 & 403 \\
Langley, Canada & 19 & 180 \\
\hline
\end{tabular}

$300 \mathrm{ppbv}$ in one case and the $\mathrm{O}_{3}$ was higher than $45 \mathrm{ppbv}$ in the other. Unlike the double selection criteria used in panels $\mathrm{A}-\mathrm{C}$, a single criterion is used in panel $\mathrm{D}$ due to the lack of $\mathrm{CO}$ data during periods of relatively elevated $\mathrm{O}_{3}$ concentrations. However, the relatively elevated $\mathrm{O}_{3}$ and $\mathrm{CO}$ periods were mutually exclusive when both datasets were available. The relatively high $\mathrm{O}_{3}$ concentrations were mostly observed during the first few days of the experiment at both the Slocan Park and Langley sites in what appeared to be a photochemical episode (only the Langley data are shown here). This graph compares the organic particulate size distribution under the two conditions of fresh emissions and photochemical processing at this location. During the relatively high $\mathrm{CO}$ periods the accumulation mode organics remained around $400 \mathrm{~nm}$ and a more significant secondary mode was observed below $200 \mathrm{~nm}$. No significant organic loading below $100 \mathrm{~nm}$ was observed, unlike at the urban sites, showing that even in such elevated pollution conditions the small particles, seen at Slocan and Manchester, were not observed at Langley. They cannot be lost by dilution in this timescale, as their concentration normalised to the Slocan Park average is many times less than the $\mathrm{CO}$ concentration normalized in the same way. There are two possible explanations, they had either been removed preferentially, though this seems unlikely, or had been processed into the mode centred at $200 \mathrm{~nm}$ during advection from the urban source region. Interestingly, the organic aerosol processing during the relatively high $\mathrm{O}_{3}$ episode seems to have increased the modal diameter of the accumulation mode from about 400 to $600 \mathrm{~nm}$ and almost doubled its mass loading. The mass spectrum in graph $\mathrm{D}$ represents an averaged organic composition during the relatively high $\mathrm{O}_{3}$ periods and shows very similar composition to that discussed in graph $\mathrm{C}$.

\section{Conclusions}

Chemical composition and mass size distribution results obtained using two Aerodyne AMS at two different sites representing urban (Slocan Park) and rural (Langley) areas during the Pacific 2001 experiment have been presented. A significant accumulation mode with a peak around $400-500 \mathrm{~nm}$ was observed at both sites and was principally composed of sulphate, organics, ammonium and some nitrate. A significant organic mass mode at about $100-200 \mathrm{~nm}$ was constantly observed at the Slocan Park site and when fresh air masses affected the Langley site. The variability of the organic particulate composition and size distribution as a function of location and photochemical activity has been discussed. The small organic mode at the urban site was found to be highly correlated with gas phase $\mathrm{CO}$, 1,3-butadiene, benzene and toluene with Pearson's $r$ values of $0.76,0.71,0.79$ and 0.69 , respectively. These strong correlations suggest that combustion-related emissions (likely dominated by traffic) are the main source of the small organic mode at this site. Similar to the composition of lubricating oil and diesel exhaust aerosol, urban organic particulate appeared to be composed of a mixture of $n$-alkanes, branched alkanes, cycloalkanes, and aromatics. The accumulation mode appeared to be composed of highly oxidized organic compounds and was significantly enhanced and dominated the distribution during an episode of intensive photochemistry at the start of the study at Slocan Park. In contrast to the urban site, organic particulate at the Langley rural site appeared to be dominated by oxidized compounds with shorter carbon chains. Correlations between the two organic modes and gas phase compounds at Langley indicated that a significant part of the small mode originated from combustion sources, while the large accumulation organic mode appeared to be the result of photochemical processing. Processing of organic particulate during a relatively high $\mathrm{O}_{3}$ episode at Langley seemed to have increased the modal diameter of the accumulation mode from about 400 to $600 \mathrm{~nm}$ and almost doubled its mass loading.

\section{Acknowledgements}

Funding for this project was provided by Environment Canada, the Georgia Basin Ecosystem Initiative and the Panel on Energy Research and Development (PERD). The authors wish to thank K. Analuf for CO, $\mathrm{NO}, \mathrm{NO}_{2}, \mathrm{NO}_{y}, \mathrm{SO}_{2}$ and $\mathrm{O}_{3}$ data, Daniel Wang for 1,3butadiene, benzene and toluene data, Jan Bottenhiem for PAN data, Ken Stubbs from the Greater Vancouver Regional District, John Deary from Meteorological Service of Canada, Bruce Thomson and Wayne Belzer for technical support and others from the Environment Canada Pacific and Yukon Region. M. R. Alfarra would like to thank Universities UK, UMIST and Karim Rida Said Foundation for their financial support. The 
UMIST AMS was supported through NERC Grant GR3/12499.

\section{References}

Allan, J.D., Jimenez, J.L., Williams, P.I., Alfarra, M.R., Bower, K.N., Jayne, J.T., Coe, H., Worsnop, D.R., 2003a. Quantitative sampling using an Aerodyne aerosol mass spectrometer - 1 . Techniques of data interpretation and error analysis. Journal of Geophysical Research-Atmospheres 108 (D3) art. no.-4090.

Allan, J.D., Alfarra, M.R., Bower, K.N., Williams, P.I., Gallagher, M.W., Jimenez, J.L., McDonald, A.G., Nemitz, E., Canagaratna, M.R., Jayne, J.T., Coe, H., Worsnop, D.R., 2003b. Quantitative sampling using an Aerodyne aerosol mass spectrometer-2. Measurements of fine particulate chemical composition in two U.K. cities. Journal of Geophysical Research-Atmospheres 108 (D3) art. no.4091.

Allan, J.D., Bower, K.N., Coe, H., Boudries, H., Jayne, J.T., Canagaratna, M.R., Millet, D.B., Goldstein, A.H., Quinn, P.K., Weber R.J., Worsnop, D.R., 2004a. Submicron aerosol composition at Trinidad Head, CA during ITCT $2 \mathrm{~K} 2$, its relationship with gas phase volatile organic carbon and assessment of instrument performance. Journal of Geophysical Research-Atmospheres 109 (D23), D23S24.

Allan, J.D., Delia, A.E., Coe, H., Bower, K.N., Alfarra, M.R., Jimenez, J.L., Middlebrook, A.M., Drewnick, F., Onasch, T.B., Canagaratna, M.R., Jayne, J.T., Worsnop, D.R., 2004b. A generaslised method for the extraction of chemically resolved mass spectra from Aerodyne aerosol mass spectrometer data. Journal of Aerosol Science 35 (7), 909-922.

Boudries, H., Canagaratna, M.R., Jayne, J.T., Alfarra, M.R., Allan, J.D., Bower, K.N., Coe, H., Pryor, S.C., Jimenez, J.L., Brook, J.R., Li, S., Worsnop, D.R., this issue. Chemical and Physical Processes Controlling the Distribution of Aerosol in the Lower Fraser Valley, Canada, During the Pacific 2001 filed campaign. Atmospheric Environment.

Brook, R.D., Brook, J.R., Urch, B., Vincent, R., Rajagopalan, S., Silverman, F., 2002. Inhalation of fine particulate air pollution and ozone causes acute arterial vasoconstriction in healthy adults. Circulation 105 (11), 1534-1536.

Canagaratna, M.R., Jayne, J.T., Ghertner, D.A., Herndon, S., Shi, Q., Jimenez, J.L., Silva, P.J., Williams, P., Lanni, T., Drewnick, F., Demerjian, K.L., Kolb, C.E., Worsnop, D.R., 2004. Chase Studies of Particulate Emissions from inuse New York City Vehicles. Aerosol Science and Technology, in press.

Castro, L.M., Pio, C.A., Harrison, R.M., Smith, D.J.T., 1999. Carbonaceous aerosol in urban and rural European atmospheres: estimation of secondary organic carbon concentrations. Atmospheric Environment 33 (17), 2771-2781.

Charlson, R.J., Schwartz, S.E., Hales, J.M., Cess, R.D., Coakley, J.A., Hansen, J.E., Hofmann, D.J., 1992. Climate forcing by anthropogenic aerosols. Science 255 (5043), 423-430.

Dockery, D.W., Pope, C.A., Xu, X.P., Spengler, J.D., Ware, J.H., Fay, M.E., Ferris, B.G., Speizer, F.E., 1993. An Association between air-pollution and mortality in 6 United
States Cities. New England Journal of Medicine 329 (24), 1753-1759.

Drewnick, F., Schwab, J.J., Hogrefe, O., Peters, S., Husain, L., Diamond, D., Weber, R., Demerjian, K.L., 2003. Intercomparison and evaluation of four semi-continuous PM2.5. sulfate instruments. Atmospheric Environment 37, 3335-3350.

Drewnick, F., Schwab, J.J., Jayne, J.T., Canagaratna, M.R., Worsnop, D.R., Demerjian, K.L., 2004a. Measurement of ambient aerosol composition during the PMTACS-NY 2001 using an aerosol mass spectrometer. Part I: mass concentrations. Aerosol Science and Technology 38 (S1), 92-103.

Drewnick, F., Jayne, J.T., Canagaratna, M.R., Worsnop, D.R., Demerjian, K.L., 2004b. Measurement of ambient aerosol composition during the PMTACS-NY 2001 using an aerosol mass spectrometer. Part II: chemically speciated mass distributions. Aerosol Science and Technology 38 (S1), 104-117.

Fenger, J., 1999. Urban air quality. Atmospheric Environment 33 (29), 4877-4900.

Gray, H.A., Cass, G.R., Huntzicker, J.J., Heyerdahl, E.K., Rau, J.A., 1986. Characteristics of atmospheric organic and elemental carbon particle concentrations in Los Angeles. Environmental Science and Technology 20, (580-582).

GVRD 2002. 2000 Emission Inventory for the Lower Fraser Valley Airshed. Greater Vancouver Regional District, Policy \& Planning Department, Burnaby. B.C.

Harley, R.A., Cass, G.R., 1995. Modeling the atmospheric concentrations of individual volatile organic compounds. Atmospheric Environment 29 (8), 905-922.

Hildemann, L.M., Rogge, W.F., Cass, G.R., Mazurek, M.A., Simoneit, B.R.T., 1996. Contribution of primary aerosol emissions from vegetation-derived sources to fine particle concentrations in Los Angeles. Journal of Geophysical Research 101, 19541-19549.

Hogrefe, O., Drewnick, F., Lala, G., Schwab, J.J., Demerjian, K.L., 2004. Development, operation and application of an aerosol generation, calibration and research facility. Aerosol Science and Technology 38 (S1), 196-214.

Jayne, J.T., Leard, D.C., Zhang, X.F., Davidovits, P., Smith, K.A., Kolb, C.E., Worsnop, D.R., 2000. Development of an aerosol mass spectrometer for size and composition analysis of submicron particles. Aerosol Science and Technology 33 (1-2), 49-70.

Jimenez, J.L., Jayne, J.T., Shi, Q., Kolb, C.E., Worsnop, D.R., Yourshaw, I., Seinfeld, J.H., Flagan, R.C., Zhang, X., Smith, K.A., Morris, J.W., Davidovits, P., 2003a. Ambient aerosol sampling using the aerodyne aerosol mass spectrometer. Journal of Geophysical Research-Atmospheres 108 (D7) art. no.-8425.

Jimenez, J.L., Bahreini, R., Cocker, D.R., Zhuang, H., Varutbangkul, V., Flagan, R.C., Seinfeld, J.H., O’Dowd, C.D., Hoffmann, T., 2003b. New particle formation from photooxidation of diiodomethane (CH2I2). Journal of Geophysical Research-Atmospheres 108 (D10) art. no.4318.

Kane, D.B., Johnston, M.V., 2000. Size and composition biases on the detection of individual ultrafine particles by aerosol mass spectrometry. Environmental Science and Technology 34 (23), 4887-4893. 
Li, S.-M., this issue. A concerted effort to understand the ambient particulate matter in the Lower Fraser Valley: the Pacific 2001 air quality study. Atmospheric Environment, this issue, doi:10.1016/j.atmosenv.2004.04.038.

Li, S.-M., Anlauf, K.G., Wiebe, H.A., Bottenheim, J.W., Shepson, P.B., Biesenthal, T., 1997. Emission ratios and photochemical production efficiencies of nitrogen oxides, ketones, and aldehydes in the lower Fraser Valley during the summer pacific 1993 oxidant study. Atmospheric Environment 31 (14), 2037-2048.

Liu, P., Ziemann, P.J., Kittelson, D.B., McMurry, P.H., 1995a. Generating particle beams of controlled dimensions and divergence: I. Theory of particle motion in aerodynamic lenses and nozzle expansions. Aerosol Science and Technology 22 (3), 293-313.

Liu, P., Ziemann, P.J., Kittelson, D.B., McMurry, P.H., 1995b. Generating particle beams of controlled dimensions and divergence: II. Experimental evaluation of particle motion in aerodynamic lenses and nozzle expansions. Aerosol Science and Technology 22 (3), 314-324.

McLafferty, F.W., Turecek, F., 1993. Interpretation of mass spectra. University Science Books, Mill Valley, CA.

Middlebrook, A.M., Murphy, D.M., Thomson, D.S., 1998. Observations of organic material in individual marine particles at Cape Grim during the first aerosol characterization experiment (ACE 1). Journal of Geophysical Research 103, 16475-16483.

Pandis, S.N., Harley, R.A., Cass, G.R., Seinfeld, J.H., 1992. Secondary organic aerosol formation and transport. Atmospheric Environment 26A, 2269-2282.

Pope, C.A., Burnett, R.T., Thun, M.J., Calle, E.E., Krewski, D., Ito, K., Thurston, G.D., 2002. Lung cancer, cardiopulmonary mortality, and long-term exposure to fine particulate air pollution. Journal of the American Medical Association 287 (9), 1132-1141.

Press, W.H., 1992. Numerical recipes in C: the art of scientific computing. Cambridge University Press, Cambridge.
Ravishankara, A.R., 1997. Heterogeneous and multiphase chemistry in the troposphere. Science 276 (5315), 1058-1065.

Saxena, P., Hildemann, L.M., 1996. Water-soluble organics in atmospheric particles: a critical review of the literature and application of thermodynamics to identify candidate compounds. Journal of Atmospheric Chemistry 24, 57-109.

Tobias, H.J., Beving, D.E., Ziemann, P.J., Sakurai, H., Zuk, M., McMurry, P.H., Zarling, D., Waytulonis, R., Kittelson, D.B., 2001. Chemical analysis of diesel engine nanoparticles using a nano- DMA/thermal desorption particle beam mass spectrometer. Environmental Science and Technology 35 (11), 2233-2243.

Tobias, H.J., Ziemann, P.J., 2000. Thermal desorption mass spectrometric analysis of organic aerosol formed from reactions of 1-tetradecene and O-3 in the presence of alcohols and carboxylic acids. Environmental Science and Technology 34 (11), 2105-2115.

Turpin, B.J., Huntzicker, J.J., 1991. Secondary formation of organic aerosol in the Los-Angeles Basin - a descriptive analysis of organic and elemental carbon concentrations. Atmospheric Environment Part a-General Topics 25 (2), 207-215.

Turpin, B.J., Huntzicker, J.J., 1995. Identification of secondary organic aerosol episodes and quantitation of primary and secondary organic aerosol concentrations during SCAQS. Atmospheric Environment 29 (23), 3527-3544.

Weingartner, E., Burtscher, H., Baltensperger, U., 1997. Hygroscopic properties of carbon and diesel soot particles. Atmospheric Environment 31 (15), 2311-2327.

Zhang, X.F., Smith, K.A., Worsnop, D.R., Jimenez, J., Jayne, J.T., Kolb, C.E., 2002. A numerical characterization of particle beam collimation by an aerodynamic lens-nozzle system: Part I. An individual lens or nozzle. Aerosol Science and Technology 36 (5), 617-631. 